\title{
An Application of Total Physical Response to Primary English Teaching-A Case Study of Qingtong Primary School
}

\author{
FENG Shan-shan \\ Ningbo Dahongying University, Ningbo, China
}

\begin{abstract}
Total Physical Response (TPR) method put forward by American psychology professor Asher advocates linking language and behavior, teaching the foreign language through body movements, and emphasizing teaching in real situations. Based on TPR method, this paper uses empirical research, literature reference, and questionnaire survey to explore problems of teachers and pupils in the traditional English teaching classroom. Compared to the traditional teaching method, TPR method in primary school English classroom greatly improves both teachers and students whether in teaching or in learning. In this research, 60 pupils from Class 3 and Class 4 in Qingtong Primary School in Huzhou City are taken as subjects, who are taught respectively by TPR method and the traditional teaching method. By contrast, the paper pinpoints advantages of TPR method and disadvantages of the traditional teaching method; by interviewing questionnaire and observation, it analyzes problems existing in English teaching from the perspectives of teachers and pupils and proposes some advice based on TPR method, meantime, stresses the combination of TPR method and other teaching methods according to different teaching situations and teaching objectives, in order to enhance the efficiency of teachers' teaching and pupils' learning in primary English teaching.
\end{abstract}

Keywords: TPR method, teachers' teaching in primary school, empirical study

\section{Introduction}

As a most widely used language, English plays an important role in the modernization development of China. In the past decades, English has made a great contribution to the development of Chinese education. With the development of Chinese economic level, a growing number of Chinese parents attach great importance to the cultivation of their children. Although students have learned English for many years, they still cannot speak it very well, including some high-achieving students. Therefore, it is vital to find an appropriate method that can encourage students to participate actively and learn more efficiently. Total Physical Response (TPR) method, as a unique language teaching method, was created by American psychology professor Asher and Hamilton (1998) points out that on the basis of abstract thinking, TPR method focuses on the improvement, which is perfectly suitable for English beginners in primary schools. Teachers should combine body movement with English learning in vivid teaching situations and teach English through body movement. While students listen to the teacher, they improve the ability of listening, speaking, reading, and writing by corresponding imitations, which

FENG Shan-shan, undergraduate, College of Humanities, Ningbo Dahongying University. 
can strengthen students' ability of thinking and enhance their learning efficiency. The paper pinpoints the advantages of TPR method and disadvantages of the traditional teaching method in primary English class by interviewing questionnaire and observation, analyzes problems in English teaching from the perspectives of teachers and pupils, and proposes some advice for the improvement of English teaching in primary schools.

\section{Literature Review}

Good English is an admission ticket for learners who want to be admitted to institutions of higher education at home and abroad. There are some opinions from foreign scholars about how to learn English easily and effectively in the first learning stage. Gaab (2006) points out that accompanying with the visual body language and auxiliary gestures, spatial image, spatial memory, and voice deformation, TPR method can make students learn knowledge as much as possible based on comprehension. Asher (1977) says that TPR method follows the rules of language acquisition and English learners need to remember the language target through body movement. They open their mouths to speak English gradually and start memorizing and accepting error correction by TPR method. Krashen (2003) thinks that teachers should not concentrate on correcting mistakes whatever language you learn, on the contrary, they should create a relaxing atmosphere to encourage students to learn more efficiently so that students can achieve their goals. Ramiro (2007) points out that TPR method particularly focuses on listening and speaking, pays attention to language meaning rather than form, and tends to cultivate students' practical ability and communicative competence with target language. The above scholars regard TPR method as a method which greatly helps students learn primary English more efficiently and abide by the rules of second language learning.

In addition, TPR method receives more and more attention from Chinese researchers. SU Bing (1995), by contrasting TPR method with the traditional English teaching method, pinpoints advantages of TPR method and proposes some English teaching modes well suited to children in the light of TPR method such as intuitive teaching method, English alphabet board teaching method, etc. WANG Min (2005) thinks that TPR method should be combined with other teaching methods, vary with different situations and teaching objectives, and it should be used flexibly to be able to acquire the best results of class teaching. FENG Li-na (2009) holds that by combining body movement with language, TPR method helps learners increase their confidence of second language learning. SHAO Qi (2010) deems that in primary schools, TPR method should be used as frequently as possible, which enables students not only to learn second language in a relaxed environment but also to have the opportunity to open their mouths and speak English, thus stimulating their enthusiasm for English learning. The above Chinese researchers notice advantages of TPR method and give some advice about how to use the method correctly.

This paper, based on the research achievements and the relevant teaching practice of researchers at home and abroad, is aimed at applying TPR method to primary English class in order to enhance the efficiency of teachers' teaching and pupils' learning in primary English teaching.

\section{TPR Method}

TPR method, as a unique language teaching method, was created by American psychologist James J. Asher. It is called a new form of direct method because of its similarity to direct method. TPR method can stimulate 
students' interest and make them actively participate in learning, which is appropriate for foreign language beginners in primary schools. The method has four main characteristics. Firstly, learning comprehension is preferred. Teachers are required to cultivate students' ability of listening comprehension in the first place, which is quite necessary for students' oral ability. Secondly, students are expected to improve their comprehension through physical response to language. Thirdly, Students are allowed to make a statement with preparation in advance; meanwhile, teachers do not force students to speak. Fourthly, teachers are supposed to pay attention to the significance of teaching rather than the form of teaching; they are supposed to teach the target language by body action, which helps strengthen students' ability of thinking and enhance their learning efficiency, thus eliminating dumb English.

\section{Research Methodology}

This research takes as subjects pupils of two classes in Qingtong Primary School in Huzhou City, who are taught respectively by TPR method and the traditional teaching method, adopts the questionnaire survey to contrast and analyze advantages of the application of TPR method to primary school and improve it greatly, compared to the traditional teaching method in primary English class. Through the questionnaire, advantages of TPR method become more obvious and persuasive. The research is composed of four parts, which are subjects, instrument, procedures, data collection, and results.

\section{Subjects}

The research takes as subjects 60 pupils from Class 3 and Class 4 and the reasons for it are as follows: Firstly, the class size and the ratio of male and female, even academic records are almost the same, which does not bother the research results greatly; secondly, Class 3 is the first period of English learning for pupils so that their interest and level of English learning is at a level, which can reduce the difficulty of the research, thus making the research more reliable and persuasive.

\section{Instrument}

The instrument applied in this research is a questionnaire. The questionnaire is used to collect data of the questions and the data are shown directly to illustrate results. The following is a brief description of the instrument. There are altogether 20 questions in the questionnaire, in which 13 are for pupils and six for teachers, and only one is needed for pupils to write down their own opinions. There are three or five options for each question and different options reflect different effects between TPR method and the traditional teaching method in English class and the improvement of teachers' teaching methods. In consideration of the fact that the subjects are pupils, all these questions are raised in Chinese to avoid misunderstanding. The participants are required to make choices according to their feelings and experiences.

\section{Procedures}

In order to guarantee the validity and reliability of the research, pupils are required to fill out the questionnaire. 60 pupils are selected from two classes and 60 valid questionnaires are collected. All the data of the exams and questionnaires are collected to make comparison and analysis with the help of Excel.

\section{Data Collection and Results}

The data are collected from Class 3 and Class 4. 60 questionnaires collected from the pupils prove valid. 
And the following are the results of the research. The following two tables are used to analyze whether pupils are more interested in TPR method, whether scores are increased by TPR method, whether pupils are more active in English class and whether pupils have less pressure in English class. Based on the questionnaire, it comes to conclusion that the pupils all have more interest in TPR method than the traditional teaching method. Especially in Class 4, 73 percent of pupils think that TPR method is more interesting; about 60 percent choose the "Increased" in the improvement of scores, which reflects TPR method is effective. Most of pupils are active with TPR method. In the item "Whether pupils have less pressure in English class", over 40 percent of pupils in Grade 5 say "Not pressured", which indicates that TPR method enables pupils to be relaxed in English class.

Table 1

Influences of TPR Method on Pupils' English Learning

\begin{tabular}{llllll}
\hline \multirow{2}{*}{ Class } & & \multicolumn{2}{c}{ Class 3 } & \multicolumn{2}{c}{ Class 4 } \\
\cline { 3 - 5 } & & Number & Percentage & Number & Percentage \\
\hline \multirow{2}{*}{$\begin{array}{l}\text { Whether pupils are more interested in } \\
\text { TPR method }\end{array}$} & Interested & 20 & $67 \%$ & 22 & $73 \%$ \\
& Average & 6 & $20 \%$ & 5 & $17 \%$ \\
\hline \multirow{2}{*}{$\begin{array}{l}\text { Whether scores are increased by TPR } \\
\text { method }\end{array}$} & No interest & 4 & $13 \%$ & 3 & $10 \%$ \\
& Increased & 18 & $60 \%$ & 20 & $67 \%$ \\
& Average & 7 & $23 \%$ & 6 & $20 \%$ \\
\hline
\end{tabular}

Table 2

Influences of TPR Method on Teachers' English Teaching

\begin{tabular}{llllll}
\hline \multirow{2}{*}{ Class } & & \multicolumn{3}{c}{ Class 3 } & Class 4 \\
\cline { 3 - 6 } & & Number & Percentage & Number & Percentage \\
\hline \multirow{2}{*}{ Whether pupils are } & Active & 21 & $70 \%$ & 23 & $77 \%$ \\
more active in & Average & 4 & $13 \%$ & 3 & $10 \%$ \\
English class & Not active & 5 & $17 \%$ & 4 & $13 \%$ \\
\hline \multirow{2}{*}{$\begin{array}{l}\text { Whether pupils have } \\
\text { less pressure in }\end{array}$} & Pressured & 9 & $30 \%$ & 7 & $23 \%$ \\
English class & Average & 8 & $27 \%$ & 6 & $20 \%$ \\
\hline
\end{tabular}

\section{Findings}

By the analyzing the research results, it concludes that the traditional teaching method has some weaknesses in English class. On the contrary, TPR method is much better than the traditional teaching method. The following is the detailed comparison and analysis of the application of the traditional teaching method and TPR method to English class.

\section{Problems in Traditional Primary English Class}

In traditional primary English class, it can be found that some problems inevitably prevent pupils form learning English, which are given from two perspectives.

Silent attitude of pupils. It is considered to be a universal phenomenon that pupils keep silent in English class. Pupils have low enthusiasm when teachers ask them questions. Though students have ideas about the questions, they would not raise their hands and answer. Most of students are only listeners as if they had nothing to do with class teaching. The silent phenomenon in English class can result from several reasons: failure to know 
the answer, to understand the question; or to be sure about the answer. The silent phenomenon and teachers' teaching method are inseparable as teachers are main organizers and managers in class.

Low teaching efficiency of teachers. The relationship between teachers and students is the most basic relationship in the whole class, in which teaching is not student-centered but teacher-centered at present. At the same time, teachers emphasize whether their class teaching goes on schedule but ignore whether pupils are absorbed into what they learn. Teachers are leaders and organizers in class teaching and strictly control everything about teaching process so that they give questions for pupils to answer, whose solutions are provided by teachers and pupils have no opportunities to put up questions and they are first and last in a passive and negative teaching state. In teaching, teachers only focus on imparting knowledge to pupils, not realizing the importance of efficient and appropriate teaching method, which leads to low efficiency of class teaching.

\section{Advantages of TPR Method in Primary English Class}

By contrasting with the traditional English class teaching, advantages of TPR Method are undoubtedly obvious.

Pupils' enthusiasm for English class. Through the application of TPR method to English class, it is obviously noticed that pupils' enthusiasm for English learning is improved so greatly that they actively participate in activities in class teaching. When they are asked questions, they answer quickly and listen carefully. In addition, the method helps inspire pupils' original intention about English learning, thereby improving their confidence greatly, which is seen in Table 1 .

Effective improvement of English teaching. Pupils have less life experience and less contact with foreign language learning, however, they have much talent for learning and grasping foreign language; meanwhile, they are so active and smart that they are more interested in English learning. If teachers apply TPR method to class teaching, pupils are well possible to respond to the method, for example, thinking out one word after another in a short period of time. When they are guided to speak out the related words, they are probable to speak out the complete sentence. TPR method is a progressed teaching method, with which teachers can greatly improve their teaching efficiency, which is seen in Table 2.

\section{Improvement of TPR Method}

In view of the application of TPR method to primary schools, it also needs to be improved for better teaching efficiency.

\section{Implementing Principles of TPR Method}

In order to enhance teaching efficiency of class teaching, teachers should obey the following principles in teaching based on TPR method.

Combination of listening and speaking. TPR method stresses on developing students' ability of listening and speaking. Hence, teachers should gradually develop their ability of speaking while training pupils' listening ability. According to universal grammar theory, language learners have the gift to learn language so that when they accept enough comprehensible language input, they tend to transform the language input into language output. Therefore, it is necessary for teachers to create an affluent and accessible language environment for pupils in English class. Generally speaking, a person finds it easy to learn English if he or she lives in English-speaking 
countries for several years. This means that when an English learner is in an English environment for some time, he or she listens to native speakers and hears from them, his or her language input is possible to reach a considerable level; in term his or her language output is found to be out of question. However, it is difficult to provide a good environment for English learning at primary school in China so that it is vital for providing pupils with an affluent and accessible language input in English class.

Understanding in action. TPR teaching method can serve as an English teaching method for instructional design. TPR method stresses that teachers should develop students' comprehension by body. Their physical reaction proceeds in line with the guidance of teachers. When applying TPR method, teachers play a very positive and directive role and decide class activities and order, in which they should obey requirements as follows: Firstly, teachers need to prepare class teaching carefully including teaching material and objectives, which is the precondition for the completion of teaching tasks; secondly, teachers need to apply lots of learning theories to teaching; and thirdly, teachers need a strong ability of organization and management of class. It is worth noting that educational activities and purpose should not be ignored.

Combination of different teaching methods. The significance of TPR method is not the language form. Teachers should hold a tolerant attitude and decrease their tension when facing students' mistakes. ZHANG Yuan-hong (2000) points out that teachers should not always correct mistakes; otherwise, students would be afraid of making mistakes and do not dare to speak out. Under the circumstances, teachers should adopt various teaching methods for the improvement of teaching quality such as performances, games, scenes, which may stimulate pupils' interest in English learning and improve the effectiveness of class teaching. Gouin (1894) holds that combining TPR method with other teaching methods helps not only to teach words and phases but also to teach grammar and texts. Moreover, teachers should adopt TPR method flexibly in interactive class teaching.

Whole teaching staff's participation. TPR method highlights a relaxed and happy atmosphere for language learning. Therefore, teachers should not force students to speak out before they are well prepared. Humanistic teaching method also thinks that a low pressure and relaxing state is beneficial to language learning. The relaxing state does not mean indulgence. PENG Jin-qi (2009) pinpoints that that students are the main factors in class and the degree of students' participation is the direct reflection of successful class teaching. If teachers want to get their satisfied result of class teaching, they should organize class teaching as well as they pay attention to students' participation. To achieve the purpose, firstly, teachers' educational concept should keep pace with the era, which is important to innovate class teaching and conduct student-centered class teaching; the second is that teachers should fully understand students and make class teaching directed to all the students, meantime, teaching requires the full participation of the whole teaching staff. Therefore, all the teachers should reinforce their participatory awareness and improve students' enthusiasm for English class, thus making them all participants of class teaching; and finally, teachers should influence students with their positive and optimistic mind.

\section{Implication}

The research aims to find problems existing in primary English class and to explore the application of TPR method to English class. The method can make up for deficiencies of the traditional teaching method. From the results of the questionnaire, it concludes that TPR method is suitable for pupils with distraction conduct and 
strong self-esteem and it makes students put in a relaxed state, thus enabling them to gain a better achievement without pressure, which lays the solid foundation for students' foreign language ability. Moreover, TPR method is a novel and valid teaching method for primary English teachers, which provides a new teaching method for primary English teachers, which helps to eliminate dumb English.

\section{Conclusion}

This paper mainly takes as subjects 30 pupils in Class 3 and 30 pupils in Class 4 in Qingtong Primary School in Huzhou City in the form of the questionnaire survey to compare Total Physical Response (TPR) with traditional teaching method, thus showing advantages of TPR method in primary English class and improving TPR method. There are two problems in traditional primary English class, namely, silent attitude of pupils and low teaching efficiency of teachers. TPR method applied to primary English class stimulates pupils' enthusiasm for English class and improves the efficiency of English teaching. By contrast, it is concluded that TPR method is more effective than the traditional teaching method. TPR method can increase pupils' English interest and motivate their creativity and provide a relaxing atmosphere. Carols Efeldt and Nita Barbour (1986) point out that TPR method can solve the problems that students are too young to control themselves and focus attention. Besides, in order to improve the teaching level, teachers should improve TPR method and obey the following principles: combination of listening and speaking, understanding in action, and combination of different teaching methods. In a word, TPR method is worthy to be used in primary English class across China. Although this research has some limits, it can be used to some degree to help pupils improve their learning efficiency and teachers' teaching level.

\section{References}

FENG, L. N. (2009). An analysis of TPR method. The Science Education Article Collects, 43, 27-34.

Gaab, C. (2006). TPRS: Evolution or creation? Language Magazines, 57, 36-40.

Gouin, F. (1894). The art of teaching and studying language. London: George Philip and Son.

Hamilton, C. R. (1998). Paths in the brain, actions of the mind: Special issue in Honor of Roger W. Sperry. Neuropsychology, 36(10).

James, J. A. (1977). Children learning another language: A developmental hypothesis. Child Development, 48, 1040-1048.

Krashen, S. D. (2003). Exploration in language acquisition and language use: The Taipei lectures. Portsmouth, NH: Heinemam.

PENG, J. Q. (2009). On features of TPR teaching skills and training measures. Journal of Social Science of Hunan Medical University, 28, 17-26.

Seefeldt, C., \& Barbour, N. (1986). Early childhood education: An introduction. New York: Merrill Publishing Company. SHAO, Q. (2010). Teaching Chinese as a foreign language in TPR. Literature Education, 50, 46-52.

SU, B. (1995). An exploration of TPR method of children English teaching. Taian Journal of Teachers College, 35, 67-74.

WANG, M. (2005). An full comprehension of TPR method and its application to children English teaching. Journal of Hetao University, 18, 43-51.

ZHU, C. X. (2013). An application of TPR method to oral teaching of English beginners. Overseas English, 29, 37-44. 